\title{
Load on Trough Bellows Following Argon Spill
}

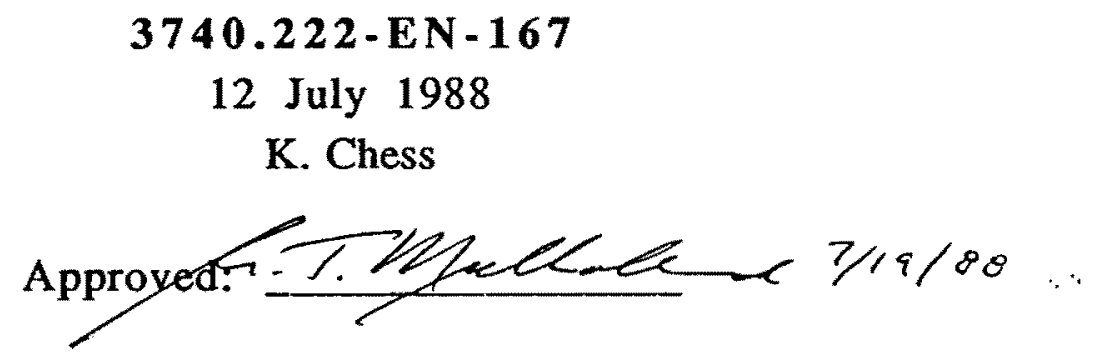




\section{INTRODUCTION}

In the case of a gross argon spill from the D0 detector, the liquid argon is caught in three plenums. These plenums are to be connected by bellows to make a horizontal trough open at one end for removing the argon. The design of these bellows is dependent on the maximum argon load they must carry.

\section{DISCUSSION-Rectangular Bellows}

To approximate this load, first consider a horizontal open channel of uniform, rectangular cross section 2.2 feet wide and 1.1 feet high (the size of the openings in the plenums) and extending 30 feet in length. In the worst case, $168 \mathrm{gal} / \mathrm{min}$ or $0.374 \mathrm{cfs}$ would spill into the plenum farthest from the open end and flow the full 30 feet to exit the trough. The profile of this flow sketched in Figure 1 shows a gradual flow beginning at $d_{o}$ and continuing to $d_{c}$, the critical depth, after which the drop in depth is more pronounced to the overfall at $d_{f}$. This critical depth is independent of the channel slope and roughness and is

$$
d_{c}=\sqrt[3]{\frac{Q^{2}}{b^{2} g}}
$$

where $d_{c}=$ critical depth, $f t$

$\mathrm{Q}=$ quantity of flow, cfs

$\mathrm{b}=$ width of channel, $\mathrm{ft}$

$\mathrm{g}=$ acceleration due to gravity, $\mathrm{ft} / \mathrm{s}^{2}$

for rectangular channels. 1 For our case, $d_{c}$ is about $0.1 \mathrm{ft}$, or 1.2 inches. Critical depth for horizontal channels occurs $11.6 \mathrm{~d}_{\mathrm{c}}$ upstream from the overfall. ${ }^{2}$ Here, this is $1.16 \mathrm{ft}$ or about 14 inches.

The depth, $d_{f}$, at the overfall is defined ${ }^{3}$ as $0.715 d_{c}$ and is $0.0715 \mathrm{ft}$ or about 0.86 inches. 
To approximate the depth, $d_{0}$, at the beginning of the channel, a useful expression is the Manning equation 4

$$
\mathrm{Q}=\frac{1.486}{\mathrm{n}} \mathrm{AR}^{2 / 3} \mathrm{~S}^{1 / 2}
$$

where $\mathbf{n}=$ Manning's roughness coefficient

$$
\begin{aligned}
& A=\text { area of flow, } \mathrm{ft} 2 \\
& \mathrm{R}=\text { hydraulic radius, } \mathrm{ft} \\
& \mathrm{S}=\text { loss of head/ linear foot. }
\end{aligned}
$$

The most appropriate value for $\mathrm{n}$ is .024 , which corresponds to corrugated-metal storm drains. We define $S$ upstream from the critical depth, where the slope is approximately constant, as

$$
\mathrm{S}=\frac{\mathrm{d}_{\mathrm{o}}-\mathrm{d}_{\mathrm{c}}}{28.8}
$$

Finally, for rectangular channels, 5

$$
A=b d \quad \text { and } \quad R=\frac{b d}{b+2 d}
$$

Difficulty arises in determining where $d$ should be measured. For our purposes, the average between the initial and critical depths is taken, so

$$
\mathrm{d}=\frac{\mathrm{d}_{0}+\mathrm{d}_{\mathrm{c}}}{2 .}
$$


With substitution, the Manning equation becomes

$$
\mathrm{Q}=\frac{1.486}{\mathrm{n}}\left(\frac{\mathrm{b}\left(\mathrm{d}_{\mathrm{o}}+\mathrm{d}_{\mathrm{c}}\right)}{2}\right)\left(\frac{\mathrm{b}\left(\mathrm{d}_{\mathrm{o}}+\mathrm{d}_{\mathrm{c}}\right)}{2\left(\mathrm{~b}+\mathrm{d}_{\mathrm{o}}+\mathrm{d}_{\mathrm{c}}\right)}\right)^{2 / 3}\left(\frac{\mathrm{d}_{\mathrm{o}}-\mathrm{d}_{\mathrm{c}}}{28.8}\right)^{1 / 2}
$$

Since all variables except $d_{o}$ are known, trial-and-error solution yields $\mathrm{d}_{\mathrm{o}}=0.22 \mathrm{ft}$ or about 2.6 inches.

For bellows with a closed length of 27 inches and an open length of 68 inches, the resulting argon load is

$$
\mathrm{W}=(\text { volume })(\text { density }) .
$$

For closed bellows $\mathrm{W}=92 \mathrm{lbs}$, and for open bellows $\mathrm{W}=231 \mathrm{lbs}$.

These weights correspond to a calculated $d_{o}$ for smooth-walled, rectangular channel. Convolution loading is an addition. A bellows carries a volume in its convolutions

$$
\mathrm{V}=0.5 \mathrm{~L} \mathrm{~A} \mathrm{~A}_{\mathrm{c}}
$$

where $L=$ length, in

$A_{c}=$ convolution cross sectional area to depth of flow, in ${ }^{2}$

The factor of 0.5 is necessary because for every inner, filled convolution there is an outer, unfilled one.

As an example, a 2.2 feet wide (inside) rectangular bellows with 2 inch deep convolutions and a flow depth of 2.6 inches carries a volume of argon in its convolutions; $V=950$ in $^{3}$ and 2394 in $^{3}$ for closed and open bellows, respectively. This corresponds to a load of $48 \mathrm{lbs}$ (closed) and $121 \mathrm{lbs}$ (open). 


\section{DISCUSSION-Circular Bellows}

Another possibility for bellows design is two circular bellows positioned in parallel. Consider now a horizontal open channel consisting of 3 pieces of rectangular cross section 2.2 feet wide, 1.1 feet high, and 5.75 feet long connected to each other by pairs of circular bellows with inner diameters of 1.1 feet and 0.625 inch deep convolutions. Again, in the worst case, $0.374 \mathrm{cfs}$ would spill into the plenum farthest from the open end and flow the full length to exit the trough.

The depth at the beginning of this new channel is comparable to that in the first example, so we use $d_{o}=2.6$ inches. Flow in the first plenum is as before, but flow through the new bellows requires an increase in depth. Since the quantity of flow, $Q$, is constant, the new set of bellows must carry the same amount of argon as the rectangular bellows did in the same amount of time. Thus, the depth in the circular bellows is such that the new flow area is the same as the flow area for the rectangular bellows $\left(A=b d_{0}\right.$, here $\left.67.6 \mathrm{in}^{2}\right)$. The flow area ${ }^{6}$ of the 2 circles is

$$
A_{c}=2\left\{R^{2}\left[\operatorname{Cos}-1\left(\frac{R-d_{n}}{R}\right)\right]-\left(R-d_{n}\right) \sqrt{2 R d_{n}-d_{n}^{2}}\right\}
$$

where $\mathbf{R}=$ circle radius, in

$$
\mathrm{d}_{\mathbf{n}}=\text { necessary depth, in }
$$

Trial-and-error solution yields $d_{n}=3.9$ inches. The load, of course, does not change. 
Convolution loading is determined in a similar manner as before (except the geometry is tougher) and is $13.2 \mathrm{lbs}$ and $33.2 \mathrm{lbs}$ for the pair of bellows, closed and open, respectively.

\section{CONCLUSIONS}

Bellows to connect the three argon-catching plenums in the D0 detector must be able to carry at least $92 \mathrm{lbs}$ of argon when closed and $231 \mathrm{lbs}$ when open, plus the load due to argon in the convolutions. Examples of such loads and the method for their calculations are contained in the Discussion.

It should be noted that a set of assumptions was used in these calculations. First, we considered a uniform channel and uniform flow. Second, we used a value for Manning's $n$ meant for a similar, but not exactly the same, case. Finally, we were forced to define an average depth, $d$, to be used to state the hydraulic radius, $R$, and area of flow, A. These facts may warrant consideration in future calculations. 


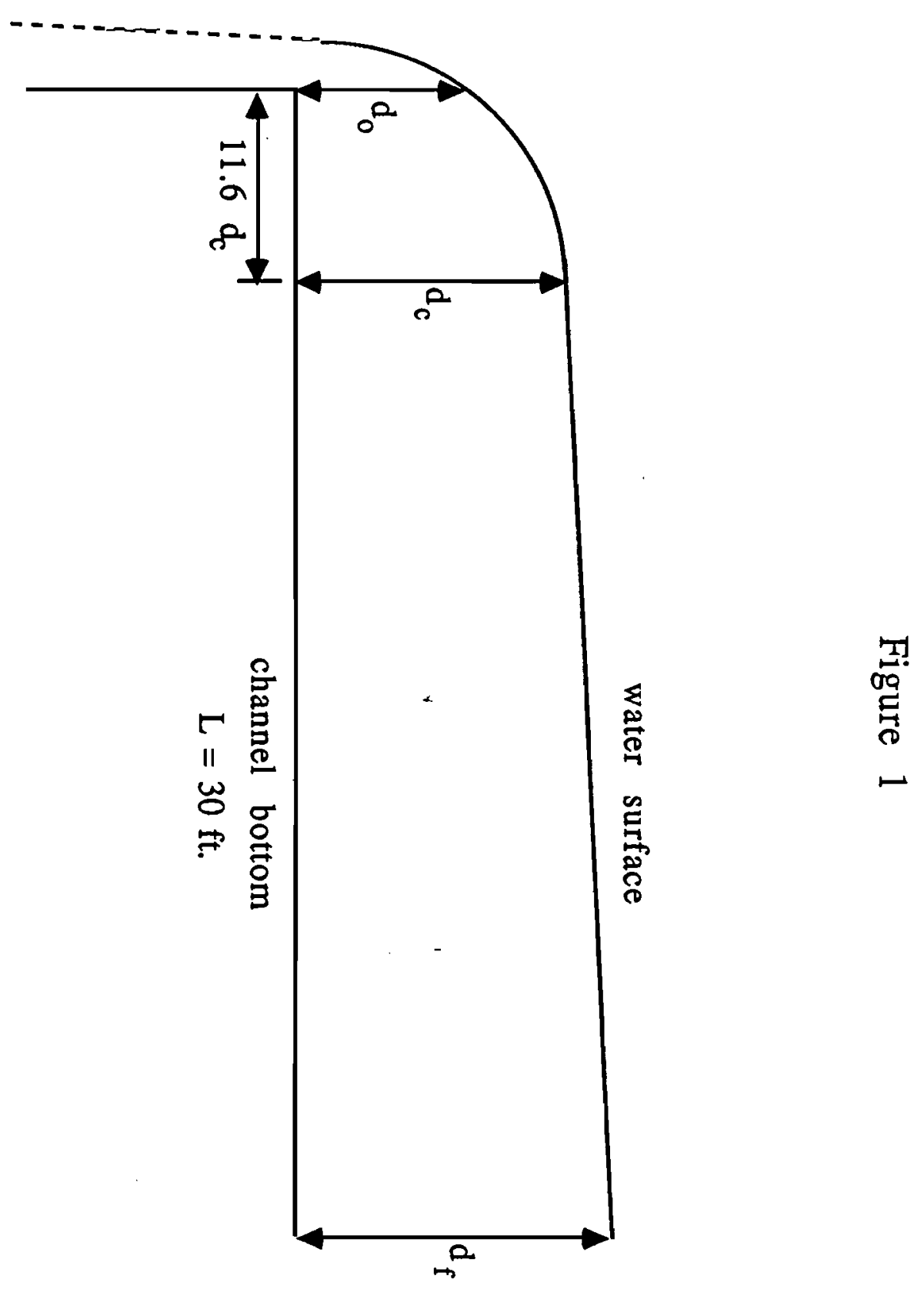




\section{CITINGS}

1. F.S. Merritt, ed, Standard Handbook for Civil Engineers. (New York: McGraw-Hill Inc., 1968) 21-46.

2. H.W. King and E.F. Brater. Handbook of Hydraulics. (New York: McGraw-Hill Inc., 1963) 8-19.

3. R.D. Blevins. Applied Fluid Dynamics Handbook. (New York: Van Nostrand Reinhold Company Inc., 1984) 208.

4. Merritt 21-45.

5. King and Brater 7-4.

6. W.H. Beyer, ed. CRC Standard Mathematical Tables: 26th Edition. (Boca Raton, Florida: CRC Press, Inc., 1981) 123. 